\title{
The Development of Blockchain Technology in Russia: Outlook and Trends
}

\footnotetext{
Submitted 19/02/19, 1st revision 07/03/19, 2nd revision 29/03/19, accepted 30/4/19

M.E. Karapetyan ${ }^{1}$, L.P. Timoshenko ${ }^{2}$, I.A. Stroganov ${ }^{3}$, I.V. Pronina ${ }^{4}$

\begin{abstract}
:
Purpose: The article addresses the issue of new scientific decisions shaping with respect to the study of problems, current trends and perspectives of blockchain technology usage in the Russian Federation.

Design/methodology/approach: To achieve the objectives of this study the increasing interest to blockchain technology in Russia was discussed.

Findings: The article determined main problems in blockchain technology which includes gaps in legislative regulation; the existence of a considerable number of projects that are undergoing the development stage and that have not proved own economic feasibility yet; incomplete understanding of the blockchain spheres' implementation by state officials, society and business representatives as well as expected outcomes according to the amount and time of their receiving; disputes on cryptocurrencies turnover in the country's territory and their influence in the national economy.

Practical implications: The study has demonstrated the interest growth mainly by businesses to the usage of blockchain technology in order to improve own competitiveness and to obtain additional benefits, including the form of their profits.

Originality/value: The research has also determined the area of further key studies in blockchain technology usage in Russia and the world.
\end{abstract}

Keywords: Bitcoin, blockchain, cryptocurrency, legal basis of regulation tendencies in market development.

JEL code: $O 00$.

Paper type: Research article.

\footnotetext{
${ }^{1}$ Stern School of Business, New York University, New York, NY, USA.

${ }^{2}$ Academic Department of Foreign Languages No.3, IBS-Plekhanov and Global Economics, Plekhanov Russian University of Economics, Moscow, Russia.

${ }^{3}$ Entrepreneurship and logistics department, Plekhanov Russian University of Economics, Moscow, Russia.

${ }^{4}$ Corresponding author, Academic Department of Foreign Languages No.3, IBS-Plekhanov and Global Economics, Plekhanov Russian University of Economics, Moscow, Russia, 1981phd@gmail.com
} 


\section{Introduction}

The emergence and the development of cryptocurrencies that are functioning today are based on blockchain technology and they have led to the increased focus of scientists, world governments, businessmen-practitioners and ordinary users on this technology. In this case, it is possible to state that blockchain has the significant potential for developing both world economy as a whole and economies of certain countries. This technology can become one of the key stimuli for the growth activation of economic systems in the developing countries. Consequently, it emphasizes the practical usage of blockchain in these countries, among them the leader is China, which is taking active actions towards studying the implementation of such a technology into business-process against the prohibition of cryptocurrencies application since September 2017 (Zhao, 2018).

It is necessary to point out that despite the fast-increasing interest in blockchain technology started in 2008 and the article Satoshi Nakamoto "Bitcoin: A Peerto-Peer Electronic Cash System" (Nakamoto, 2008), problems of blockchain and its components with the emphasis on development and implementation of cryptocurrencies have been studied by scholars, programmers and businessmenpractitioners since the 1980s of XXth century. Several works and practical attempts of digital currencies and the appropriate software development to be outlined as the followings:

- Chaum (1983) with his effort to develop and justify the usage of digital currency eCash;

- Haber and Stornetta (1990) the first researchers who addressed the technology similar to blockchain;

- Douglas Jackson and his rather successful attempt to introduce digital currency e-gold, which had golden coverage, in 1996 (Mullan, 2012);

- Adam Back, the first person who in 1997 suggested to use technology Proof-ofWork for hashcrash-system developed by him to prove the correctness of work. It was used aiming at decreasing of both spam quantity and DoS-attacks (van Wirdum, 2018);

- Szabo (2005), who developed the algorithm of decentralized digital currency in 1998. He called it BitGold;

- Vishnumurthy et al. (2003), who offered the conception of decentralized currency system operation based on technology Proof-of-Work in 2003;

- Hal Finney, who found Reusable-Proof-of-Works (RPOW) as a prototype of digital currencies in 2004 (Satoshi Nakamoto Institute, 2019).

Since 2014 in the background of active opposition of world countries' governments and their banking systems to cryptocurrencies development, focuses on studying and implementation of blockchain technology has more shifted to its usage for different spheres of national economies' development. 
Under such conditions a dual situation has occurred. On the one hand, there are mistrust and concerns about cooperation of the world and national financial and currency markets with cryptocurrencies (European Commission, 2019; Zhao, 2018). On the other hand, there is an awareness of a great development potential and the usage of blockchain technology (Government Office of Science, 2016; Swan, 2015; Tapscott and Tapscott, 2016).

In the current context scientific researches on problems of blockchain technology usage with the development of world countries' economies can be divided into two big groups:

- works that describe the technology, its advantages and disadvantages, as well as perspectives of its further implementation (Johansen, 2016; Purdon and Erturk, 2017; RAND Europe, 2019; Veuger, 2019; Wüst and Gervais, 2018);

- works that reveal possibilities and peculiarities of technology usage in particular spheres of economy (Filippova, 2018; Heston, 2019; Livingston et al., 2018; Wu and Tran, 2018).

Against this background, scientific studies on possibilities and perspectives of blockchain technology implementation to particular world countries, one of which is the Russian Federation, has been undertaken. Taking into consideration country's economic problems and availability of Russian scientists and programmers among those who are actively developing this technology, Russia has significant perspectives for stimulating the increase of its economic system with the help of blockchain. The presence of scientific developments on the issue of blockchain technology implementation to the practical activity of state institutions, economic spheres and certain enterprises of the Russian Federation has been outlined (Nosov, 2016; Tsvetkova, 2017; Yamshchikov et al., 2018). At the same time, the novelty of this technology usage demands the continuation of this problem's research and evaluation of tendencies and perspectives of its implementation in the world and some countries. The state above has allowed to formulate the goal of the scientific article. It is a detailed characterization of perspectives and current tendencies in the development of blockchain technology in Russia. Within the research goal's exposure, the following tasks are to be stated and solved step by step:

- to provide characteristics of the size of Russian blockchain market;

- to estimate tendencies in creation of a legal basis for blockchain technology regulation and the processing of bitcoins in Russia;

- to disclose the problems and peculiarities of bitcoins turnover in the Russian Federation;

- to determine problems and perspectives in the development of Russian blockchain market. 


\section{Materials and methods}

To achieve the goal of the article, the system of common scientific research methods and methods of research on empirical and theoretical levels have been used. They include the comparison method to conduct researches on the development of Russian blockchain market; the analysis and synthesis to identify trends in blockchain technology development in Russia; the method of abstraction to find problems in the development of the Russian blockchain market; methods of systematization, grouping and logical synthesis for the information systematization, generation of conclusion and scientific proposals of the article.

The methodology of the research is based mainly on historical and systematic approaches in describing and solving problems of Russian blockchain market development. The work presents the development of blockchain technology as one of the perspective influential factors on the stimulation of the Russian Federation's economy increase. The study is also based on the assumption that the usage of blockchain in Russia and the increase of the Russian market of this technology need efforts' activation of both state authorities and representatives of business entities.

\section{Results}

\subsection{The size and major players of the Russian blockchain market}

At the beginning of 2018, there were 50 registered legal entities that cited or were tangibly involved in the operations on the blockchain market in Russia (United Government Registrar of Legal Entities of Russian Federation, 2018). Out of that 50, just 38 companies emerged in 2017, 6 in 2016, and the rest (6 companies) were registered in the period of 2006-2014 (some of them were reorganized and changed their business operations to blockchain after its inception).

The main spheres of activity cited by these companies involve data processing, computer engineering, computer software development, legal and consulting services in the computer science technology. However, some companies operate in the field of wholesale trade, production and sale of radio-electronic equipment, the development of biotechnologies, leasing of intellectual property, financial consulting and educational services for children and adults.

The actual number of projects can be higher. It is explained by the fact that official data do not account for international projects in Russia, or projects performed by Russian firms overseas. Including them, the number of blockchain companies operating in Russian could reach 70-100 now (Doudy, 2018). 
According to industry experts, the 10 new blockchain projects could be launched in 2018 - all related to the projects in the public sector. "As for the private sector it is more difficult to estimate, because up to $70 \%$ of Russian economy is controlled by the government" as Igor Kalaganov said, founder of a residential leasing services firm based on the blockchain technology (Tadviser, 2018). The current market size of blockchain related business operations is estimated at RUB 1bn ( $\$ 16 \mathrm{mn})$, which is 1/100th of a percentage point of Russia's 2017 GDP. Additionally, Russian project or teams with the majority representing Russian citizens raised $\$ 300 \mathrm{mln}$ in ICO, which still accounts of just $0.02 \%$ of Russia's GDP (Center of Economic Forecasting, 2018).

Russian blockchain market is in the early stages of development, with the majority of projects planned to be implemented in 2018-2019. The previous year, 2017, was a year of an active investing stage in the blockchain projects. Moreover, most of the projects are either now being developed or on the pilot testing stage.

One of the major problems in the sector now, it the lack of public information about the blockchain projects. This problem is expected to be solved because many projects are involved in the solutions as well as services related to public sector, oil and gas, energy and the financial sector of the economy.

Examples of possible blockchain projects involve archiving the government data for one of the regional governments in Russia, the launch of the digital platform enabling the exchange of data and copyright agreements for Ministry of Education and Science of the Russian Federation. The major problems now faced by Russia in the blockchain development are: the lack of the human talent, the lack of a fully formed blockchain market and financial attractiveness for these types of projects. Other problems include the lack of clear regulatory processes, laws for the sector that limit the capital raising abilities of blockchain related companies, and projects. Nevertheless, with the introduction of the new legislation the quality of blockchain projects and its ability to compete in the marketplace will increase.

\subsection{Establishment the legal framework for digital currencies and blockchain}

Starting 2015 Central Bank of Russian Federation (CBR) started to pay closer attention to the blockchain technology, which in most cases was used for bitcoin transactions. CBR appointed the committee, the task of which was to investigate the implications of implementing the blockchain based technology for currency transactions in Russia.

The advantages of payments via blockchain include the swiftness of all transactions, low margin of errors, and its irreversibility insured by system's ability to grant access to all participants that in turn are able to verify the 
transaction's details.

Nevertheless, the general stances of Russian government officials on transactions using cryptocurrencies is negative. The head of CBR pointed out that there are increased risks of suspicious activities related to cryptocurrencies transfers. Moreover, CBR views cryptocurrency as an equivalent to money, and in Russia substitutes to Russian national currency are prohibited.

In 2016 first attempts to legalize cryptocurrencies and transactions with them appeared. Two alternatives for legalizing cryptocurrencies were discussed. One was the development of a completely new set of regulatory procedures for digital currencies called "About the regulatory framework of cryptocurrencies". While the other solution involved tweaking and amending the existing statues, when necessary, this affected multiple set of statues involving laws about payment systems, the Tax Code, laws governing the activities of Central Bank, and licensing procedures for select activities among others. There were also brief talks that cryptocurrency transactions will be criminal prosecuted. Overall, the government communicated to the market the idea that they will never recognize existing cryptocurrency as a valid payment mechanism on the territory of the Russian Federation. The technologic process behind it, however, - blockchain was worth investigating. Also talks about the development of the Russian based cryptocurrency started to emerge.

In May 2018 the law "About the digital financial assets" was passed in the Russian parliament (The State Duma). Remarkably enough, the legislation did not contain any regulatory guidelines regarding digital currency transactions, rather it just introduced the legal terminology and description of what tokens and mining are. The topic of legislation was transactions with tokens, establishing the rights of ownership, and outlining the capital raising procedures involving tokens, and regulating the token transactions. The word "cryptocurrency" was completely excluded.

Thus, the question of legalizing cryptocurrency transactions and its circulation remained unresolved. Russia's desire to mitigate risks involving cryptocurrencies, leaves little room for its development. This puts the development of cryptobusiness and its certification in Russian at a disadvantage.

Furthermore, mining activities and cryptocurrency owners will be taxed according the Russian tax laws. Individuals will be taxed with personal income tax (flat rate of 13\%), and legal entities will be taxed according to its business form (income tax for corporates is almost in all cases $20 \%$ ).

\subsection{Problems and peculiarities of bitcoin turnover in the Russian Federation}

Based on the many interviews of Russian ministers and government officials - 
bitcoin, and other cryptocurrencies, are regarded by them as a foreign project of implementing blockchain technologies that Russian legislation will never ratify as an equivalent of cash. The Chairman of the CBR Elvira Nabiullina indicated that she would not allow the use of cryptocurrencies as cash substitutes (Fadeichev, 2017). She believes that allowing the circulation of digital currencies will undermine the purchasing power of the national currency - Russian ruble.

Other controversy surrounding cryptocurrency is the question of determining its asset class, whether it is a financial instrument or is it a commodity. Determining that will allow the regulator to identify what taxation system is to be used in regards to bitcoin and similar instruments. For the example on the Russian soil the gold is taxed with Value Add Tax (Federal Law N 41-FZ, 1998), and if it determines that bitcoin is a commodity, the market for its circulation will be virtually closed. According to the Advisor to Russian President on Information Technologies German Klimenko, 20-30\% of computer in Russia are infected with virus for crypto mining (Sotnikova et al., 2017).

In March 2018, the Ninth Arbitration Court of Appeal in Moscow recognized the cryptocurrency as an asset for the first time. Previously courts in Russian considered digital currencies as a set of characters and this type of assets was not transferable. The lawsuit was filed against an individual by a collection agency to include the content of its electronic wallet to the plaintiff's assets, in order to repay their outstanding debt. At the time of a filing plaintiff held $\sim \$ 2,000$ equivalent, denominated in Russian rubles on their account.

That said, the court approved the appeal and ordered the cryptocurrency to be treated as an asset, and used to redeem the existing debt of the plaintiff. This marks the first time that the Russian court recognized the use of cryptocurrency, which in turns legalized its use on the territory of Russian Federation.

\subsection{Problems and perspectives of Russian Blockchain market development}

The most popular misconception about crypto is that it means absolutely the same thing as blockchain. A significant number of market participants believe that the popularity of crypto and blockchain is hyped, and the trend will die down eventually. They believe that the recent increase in ICO deals is a result of an unfounded excitement surrounding crypto. Moreover, most of the projects try to use blockchain in the situations where other solutions will be more effective, and the programmers mention 'blockchain' in their prospect uses to get the necessary exposure.

Nevertheless, some believe that corporate solutions utilizing blockchain technologies will be in demand. The blockchain solutions are being selected because it is "fashionable", rather it will be picked because of fundamental business and efficiency analysis indicating that using blockchain will enhance 
companies operations and increase its revenue. Blockchain projects will finally move on from the pilot stage to actual implementation in the business operations of a firm.

Today experts estimate that the big chunk of a blockchain market is divided between ICOs and similar mechanisms, related exclusively to crypto. Meanwhile, the technology itself offers tremendous opportunities in cost saving measures, customer acquisition and systems enabling the efficient interactions of employees within the organization. Currently there are myriad of new projects involving blockchain technologies, but many of them lack fineness due to the lack of developing and programming expertise, exacerbated by the fact that all programming tools are open source and virtually anyone has access to them.

Another issue with the current blockchain environment is the lack of proven and successful record of accomplishment for such projects. Only two or three projects are feasible. The possibility of blockchain implementation into the business solution will arise when the number of successful business projects reaches 2-3 per a couple dozen of businesses. In the current business environment, most of the current projects financed with ICO will fail, leaving room for a few successful ones. Even that number should enable Russian companies to become global leaders in the blockchain, subject to regulatory environment in Russia.

\section{Discussion}

From the technological viewpoint, the actual challenge comes from the ability to scale the blockchain project in such a way that it can process big amounts of data / transactions, similarly to payment transactions processed by Visa or MasterCard. There is also a need to develop tools that enable to integrate various blockchains with one another. Currently new technologies emerge to deal with this type of problems, for example to overcome the issue of limited processing power new technologies mirroring blockchain has emerged - HashGraph.

In Russia, market participants only now slowly start to understand that blockchain is just a distributed database. To develop blockchain-based business solution in isolated form from other supplementary services is difficult. Major IT service providers like SAP, have an answer of how to integrate blockchain with other technologies. They run various scenarios that enable them to intergrade blockchain with machine learning, artificial intelligence, predictive analytics, and internet of things.

Today in Russia, many blockchain projects are initiated by larger corporations, which are under the government control, in the financial services industry Sberbank and VTB. Russian government is also very interested in developing blockchain to create a transparent way of communication between the state and 
its citizen. The possible implication would allow the government to control and gather the taxes by itself foregoing the government agent - Federal Tax Service of Russian Federation.

Given the above, the goal of the article stated in the beginning of the research has been reached. The main value of the study is the characterization of problems, current trends and perspectives of blockchain technology development in Russia. Based on this information, some restrictions in this article's results implementation are to be stated, namely: the necessity to compare blockchain technology development in Russia and other countries with their division into economically developed ones and those that are developing own economic systems; the key necessity to develop methodology to estimate the efficiency of this technology implementation in the country's economy, in a certain area or at an enterprise. At the same time, stated restrictions do not reduce the practical and scientific value of the article. Moreover, they mostly characterize perspectives of further scientific researches.

\section{Conclusions}

Blockchain technology is becoming more demanding by state authorities, society, and businesses. Taking into account a short period of its operation, it is important to study problems, tendencies and perspectives of its implementation in some countries, such as the Russian Federation. The stated above proves the necessity to study blockchain technology in terms of Russia and its integration peculiarities into this county's economy against considerable disputes on the essence and the role of cryptocurrencies in the Russian economic system.

The study overtaken has allowed: to provide characteristics of the size of Russian blockchain market; to estimate tendencies of legal basis creation for the regulation of blockchain technologies and bitcoin turnover in Russia; to describe problems and peculiarities of bitcoin turnover in the Russian Federation; to determine problems and perspectives of the Russian blockchain market development.

The practical implementation of proposals and findings of the given article is to be regarded in the context of their importance for improving the efficiency of blockchain market operation in Russia and increasing of the positive impact of this technology as one of the tools to stimulate Russian economy. The perspectives for further studies based on the scientific results of this research include the granularity of several components: the role and place determination of blockchain technology in the modern economic systems; problems connected with this technology implementation to stimulate national economies development as well as the development of certain areas and business unities; ways to improve the efficiency of economic decisions development and implementation based on the usage of blockchain. 


\section{References:}

Center of Economic Forecasting. 2018. Statistical information. Available: https://www.gazprombank.ru/.

Chaum, D. 1983. Blind signatures for untraceable payments. Advances in Cryptology Proceedings of Crypto, 82(3), 199-203.

Doudy, M. 2018. State of Blockchain in Russia: 2017 Overview. Available: https://medium.com/st-finest/state-of-blockchain-in-russia-5d36bebbf132

European Commission. 2019. How blockchain-based technology has the potential to disrupt remittances worldwide. Available: https://ec.europa.eu/jrc/en/news/howblockchain-based-technology-has-potential-disrupt-remittances-worldwide

Fadeichev, S. 2017. Central Bank will not allow crypocurrencies in the Russian market as money surrogate. Available: https://tass.ru/ekonomika/4546253

Federal Law N 41-FZ. 1998. On Precious Metals and Precious Stones. Available: www.consultant.ru/document/cons_doc_LAW_18254/

Filippova, E. 2018. Blockchain Solutions for Scientific Publishing. Available: https://medium.com/crypto3conomics/blockchain-solutions-for-scientificpublishing-ef4b4e79ae2

Government Office of Science. 2016. Distributed Ledger Technology: beyond block chain. A report by the UK Government Chief Scientific Adviser. London.

Haber, S. and Stornetta, W.S. 1990. How to time-stamp a digital document. Conference on the Theory and Application of Cryptography. Springer, Berlin, Heidelberg, pp. 437-455.

Heston, T.F. 2019. The blockchain-based scientifc study. Digital Medicine, 3(2), 66-68.

Johansen, S.K. 2016. A Comprehensive Literature Review on the Blockchain Technology as an Technological Enabler for Innovation. Available: https://www.researchgate.net/publication/312592741_A_Comprehensive_Literatur e_Review_on_the_Blockchain_Technology_as_an_Technological_Enabler_for_In novation

Livingston, D., Sivaram, V., Freeman, M. and Fiege, M. 2018. Applying Blockchain Technology to Electric Power Systems. Available: https://cfrd8files.cfr.org/sites/default/files/report_pdf/Discussion_Paper_Livingston_et_al_Blo ckchain_OR_0.pdf

Mullan, C. 2012. Douglas Jackson Interview 2012 e-Gold. DGC Magazine, 50: 6-18. Available: https://ru.scribd.com/document/78434498/Douglas-Jackson-Interview2012-e-Gold

Nakamoto, S. 2013. Bitcoin: A Peer-to-Peer Electronic Cash System. Available: http://ghorr.org/wp-content/uploads/2013/08/bitcoin.pdf

Nosov, N. 2016. Perspectives of Blockchain in Russia. Available: https://www.itweek.ru/idea/article/detail.php?ID=182389

Purdon, I. and Erturk, E. 2017. Perspectives of Blockchain Technology, its Relation to the Cloud and its Potential Role in Computer Science Education. Engineering, Technology \& Applied Science Research, 7(6), 2340-2344.

RAND Europe. 2019. The Potential Role of Standards in Supporting the Growth of Distributed Ledger Technologies/Blockchain. Available: https://www.rand.org/randeurope/research/projects/blockchain-standards.html

Satoshi Nakamoto Institute. 2019. RPOW - Reusable Proofs of Work. Available: https://nakamotoinstitute.org/finney/rpow 
Sotnikova, A., Nemchenko, I. and Governors, Ye. 2017. Klimenko reported about the virus to mine bitcoins on $30 \%$ of computers. Available:

https://www.rbc.ru/technology_and_media/24/07/2017/5975d00b9a7947dce3612e $8 \mathrm{~d}$

Swan, M. 2015. Blockchain: Blueprint for a New Economy. O'Reilly Media, Sebastopol CA.

Szabo, N. 2005. Bit gold. Available: https://unenumerated.blogspot.com/2005/12/bitgold.html

Tadviser. 2018. Interview with Igor Kalaganov founder of «33 Elephants», a residential leasing services firm. Available: www.tadviser.ru

Tapscott, D. and Tapscott, A. 2016. Blockchain Revolution: How the technology behind Bitcoin is changing money, business, and the world. Penguin, New York.

Tsvetkova, L.A. 2017. Perspectives of the Blockchain technology development in Russia: Competitive advantages and barriers. Economy of the science, 3(4), 275-296.

United Government Registrar of Legal Entities of Russian Federation. 2018. Statistical information. Available: https://nalog-ru.com/egrul/

Van Wirdum, A. 2018. The Genesis Files: Hashcash or How Adam Back Designed Bitcoin's Motor Block. BITCOIN Magazin. Available:

https://bitcoinmagazine.com/articles/genesis-files-hashcash-or-how-adam-backdesigned-bitcoins-motor-block

Veuger, J. 2019. Blockchain Technology and Applications. Nova Science Pub Inc.: Hauppauge, NY.

Vishnumurthy, V. Chandrakumar, S. and Sirer, E.G. 2003. KARMA: A Secure Economic Framework for Peer-to-Peer Resource Sharing. Available: http://www.cs.cornell.edu/people/egs/papers/karma.pdf

Wu, J. and Tran, N. 2018. Application of Blockchain Technology in Sustainable Energy Systems: An Overview. Sustainability, 10, doi:10.3390/su10093067.

Wüst, K. and Gervais, A. 2018. Do you Need a Blockchain? 2018 Crypto Valley Conference on Blockchain Technology (CVCBT), 20-22, June, Zug, Switzerland, pp. 45-54.

Yamshchikov, R.V., Yamshchikova, N.V. and Zakoldaev, D.A. 2018. Blockchain technology in Russia: Achievements and problems. Bulletin of Moscow Region State University (e-journal), 2, 93-107.

Zhao, W. 2018. Blockchain technology: Development and prospects. National Science Review, nwy 133. https://doi.org/10.1093/nsr/nwy133. 